\title{
Comment on: "The spatial extent of the Deep Western Boundary Current into the Bounty Trough: new evidence from parasound sub-bottom profiling" by Horn and Uenzelmann-Neben
}

DOI:

10.1007/s11001-016-9287-y

Document Version

Accepted author manuscript

Link to publication record in Manchester Research Explorer

Citation for published version (APA):

Mitchell, N. (2016). Comment on: "The spatial extent of the Deep Western Boundary Current into the Bounty Trough: new evidence from parasound sub-bottom profiling" by Horn and Uenzelmann-Neben. Marine Geophysical Researches, 37, 371-374. https://doi.org/10.1007/s11001-016-9287-y

\section{Published in:}

Marine Geophysical Researches

\section{Citing this paper}

Please note that where the full-text provided on Manchester Research Explorer is the Author Accepted Manuscript or Proof version this may differ from the final Published version. If citing, it is advised that you check and use the publisher's definitive version.

\section{General rights}

Copyright and moral rights for the publications made accessible in the Research Explorer are retained by the authors and/or other copyright owners and it is a condition of accessing publications that users recognise and abide by the legal requirements associated with these rights.

\section{Takedown policy}

If you believe that this document breaches copyright please refer to the University of Manchester's Takedown Procedures [http://man.ac.uk/04Y6Bo] or contact uml.scholarlycommunications@manchester.ac.uk providing relevant details, so we can investigate your claim.

\section{OPEN ACCESS}


1 Comment on: "The spatial extent of the Deep Western Boundary Current

2 into the Bounty Trough: new evidence from parasound sub-bottom

3 profiling" by Horn and Uenzelmann-Neben

$4 \quad$ Neil C. Mitchell

5 School of Earth, Atmospheric and Environmental Sciences, University of Manchester,

6 Williamson Building, Oxford Road, Manchester M13 9PL, UK.

7

8 Keywords: sediment profiler records, chirp records, Milankovic cycles

10 This is the green open-access version of this article:

11 Mitchell, N.C., Comment on: "The spatial extent of the Deep Western Boundary Current into

12 the Bounty Trough: new evidence from parasound sub-bottom profiling" by Horn and

13 Uenzelmann-Neben, Marine Geophysical Research, in press

14 (https://link.springer.com/journal/11001).

17 Horn and Uenzelmann-Neben (2016) have described computing power spectra from

18 sediment profiler data collected over the Bounty Trough from which they inferred

19 Milankovic cycles. Sediment profiler records are routinely acquired on research

20 vessels, so the method presented is interesting if it can help to resolve different

21 influences on sediment deposits from such data. A significant concern, however, is

22 that attenuation dominates the amplitude variation in profiler data, distorting power

23 spectra computed over the sediment age intervals of interest. In the case of the 
24 Bounty Trough data shown, attenuation appears to have strongly varied amplitudes

25 over the depth range commensurate with the first 41 ky Milankovic cycle, so the

26 article's result is less certain than claimed. Attenuation rates can vary spatially (both

27 along track and with depth) so evaluating cycles will not be straightforward without

28 ground truth from boreholes, which potentially diminishes the utility of remote-

29 sensing data. Nevertheless, while not separating attenuation and reflectivity

30 unequivocally, alternative displays of such data as explained below can help to

31 suggest the relative importance of attenuation and reflectivity on amplitude variations.

32 The frequency analysis software of Schulz and Stattegger (1997) used by

33 Horn and Uenzelmann-Neben (2016) was originally designed to find periodic

34 variations in data series in the presence of noise. Aside from a single peak at $\sim 14.5$

$35 \mathrm{~m}$, the amplitudes shown in Figure 5a of Horn and Uenzelmann-Neben (2016)

36 decline sharply within the first $13 \mathrm{~m}$ below seabed. Amplitudes below $13 \mathrm{~m}$ are

37 generally less than $10 \%$ of the maximum amplitude. Figure 1 shows a compilation of

38 attenuation measurements, updated with data from Tyce (1981), who derived

39 sediment attenuation rates at $4 \mathrm{kHz}$ (the frequency of the data of Horn and

40 Uenzelmann-Neben (2016)). He measured attenuation rates of 0.19 to $0.63 \mathrm{~dB} \mathrm{~m}^{-1}$

41 in hemipelagic turbidites and other layered sediments broadly comparable with

42 those of the Bounty Trough. To illustrate how reflection data would be affected,

43 at $0.2 \mathrm{~dB} \mathrm{~m}^{-1}$, a halving of amplitude (a change of $6 \mathrm{~dB}$ ) occurs over $30 \mathrm{~m}$. At 0.6

$44 \mathrm{~dB} \mathrm{~m}^{-1}$, a halving of amplitude would occur over $10 \mathrm{~m}$. Given the decline in the

45 Bounty Trough data to only $10 \%$ of peak amplitude within $13 \mathrm{~m}$, the attenuation

46 coefficient may be locally extreme, perhaps even $>2 \mathrm{~dB} \mathrm{~m}^{-1}$ (this is itself

47 interesting as such high attenuation rates at $4 \mathrm{kHz}$ would commonly be

48 associated with sands, not the silty clays mainly found at Ocean Drilling Program 
Site 1122 within the study area of Horn and Uenzelmann-Neben (2016), although turbidites within these units contain some sand and the laminated structure may cause unusually high transmission loss).

An effect of attenuation can be observed in Figure 2, which shows the average of six traces of Chirp sediment profiler data collected in the central Red Sea (Mitchell et al. 2015). These data were collected with a system with frequency swept over 2-7

$\mathrm{kHz}$. They reveal prominent reflections in an area known to have climatically modulated sediment properties (during sea level lowstands of the late Pleistocene, the sea became more isolated and saline, leading to deposition of rigid aragonite-rich layers (Gevirtz and Friedman 1966; Milliman et al. 1969; Stoffers and Ross 1974)). The pair of reflections within R1 was produced by the surface of the Last Glacial Maximum sediments and by overlying Holocene sediments, while R2 to R5 represent reflections from deeper lowstand deposits. The data have been plotted in Figure 2 with amplitude on a logarithmic scale. Attenuation reduces amplitudes exponentially with propagation distance if attenuation coefficient is uniform, so the logarithm of amplitude would be expected to be linear with depth. Here, these data indeed show, below R1 (which has exaggerated amplitudes because of contrast of sediments with low-impedance water), a systematic variation with further two-way time. The straight dashed regression line fitted to the data shown implies an attenuation coefficient of $0.34 \mathrm{~dB} \mathrm{~m}^{-1}$, assuming sediment velocity of $1500 \mathrm{~m} \mathrm{~s}^{-1}$. This coefficient is potentially over-estimated because progressive compaction with depth tends to reduce density and velocity contrasts (reducing reflection amplitudes with depth), although $0.34 \mathrm{~dB} \mathrm{~m}^{-1}$ is compatible with other attenuation data on similar sediments for this $2-7 \mathrm{kHz}$ frequency band (Figure $1)$. 
The red line in Figure 3 shows the amplitude data superimposed with the attenuation trend (dashed red line). The blue line shows the effect of de-trending the data using the regression line in Figure 2 and converting the logarithmic de-trended data back into amplitudes. The principal trend in the red data is caused by the attenuation, while the de-trended data have a more episodic variation more likely to reveal periodicities if the data two-way times were transformed to sediment age. The corresponding power spectra computed using the "spectrum1d" module of the Wessel and Smith (1991) software shown in Figure 4 illustrate how dramatically spectra can sometimes differ when computed with and without de-trending.

A preferable analysis procedure would therefore be to plot $\log$ (amplitude) versus two-way time or depth. If such plots are linear, this may imply a uniform attenuation rate, which can be evaluated against other attenuation measurements as above. Even if plots are not linear, the attenuation component of any variation could be assessed knowing the range of attenuation coefficients to be expected of the target sediments. Where de-trending appears worthwhile, it also unfortunately enlarges noise with increasing two-way travel time, which produces unwanted effects on power spectra. However, noise effects could potentially be reduced by fitting periodic functions to the data series (Fourier transforming) with weighting to account for signal-to-noise ratio varying with two-way time. Interpreting sediment profiler records in terms of Milankovic cycles is likely to be complicated, but the basic step of plotting the data logarithmically as in Figure 2 may help to reveal whether variations in profiler data along tracks are genuine variations in reflectivity or are artifacts of varied attenuation.

\section{References}


99 Gevirtz JL, Friedman GM (1966) Deep-sea carbonate sediments of the Red Sea and

100 their implications on marine lithification. J. Sediment. Petrol. 36:143-151

101 Hamilton EL (1980) Geoacoustic modeling of the sea floor. J. Acoust. Soc. Am.

$102 \quad 68(5): 1313-1340$

103 Horn M, Uenzelmann-Neben G (2016) The spatial extent of the Deep Western

104 Boundary Current into the Bounty Trough: new evidence from parasound sub-

105 bottom profiling. Mar. Geophys. Res. 37:145-158

106 Milliman JD, Ross DA, Ku T-L (1969) Precipitation and lithification of deep-sea

107 carbonates in the Red Sea. J. Sed. Petrol. 39:724-736

108 Mitchell NC (1993) A model for attenuation of backscatter due to sediment

109 accumulations and its application to determine sediment thickness with GLORIA

110 sidescan sonar. J. Geophys. Res. 98:22477-22493

111 Mitchell NC, Ligi M, Rohling EJ (2015) Red Sea isolation history suggested by Plio-

112 Pleistocene seismic reflection sequences. Earth Planet. Sci. Lett. 430:387-397

113 Schulz M, Stattegger K (1997) Spectrum: spectral analysis of unevenly spaced

114 paleoclimatic time series. Comput. Geosc. 23:929-945

115 Stoffers P, Ross DA (1974) Sedimentary history of the Red Sea. in: Whitmarsh, R.B.,

116 O.E. Weser, D.A. Ross, et al., Initial reports of the Deep Sea Drilling Project U.S.

117 Government Printing Office 23:849-865

118 Tyce RC (1981) Estimating acoustic attenuation from a quantitative seismic profiler.

119 Geophysics 46(10):1364-1378

120 Wessel P, Smith WHF (1991) Free software helps map and display data. Eos,

121 Transactions, American Geophysical Union 72:441 


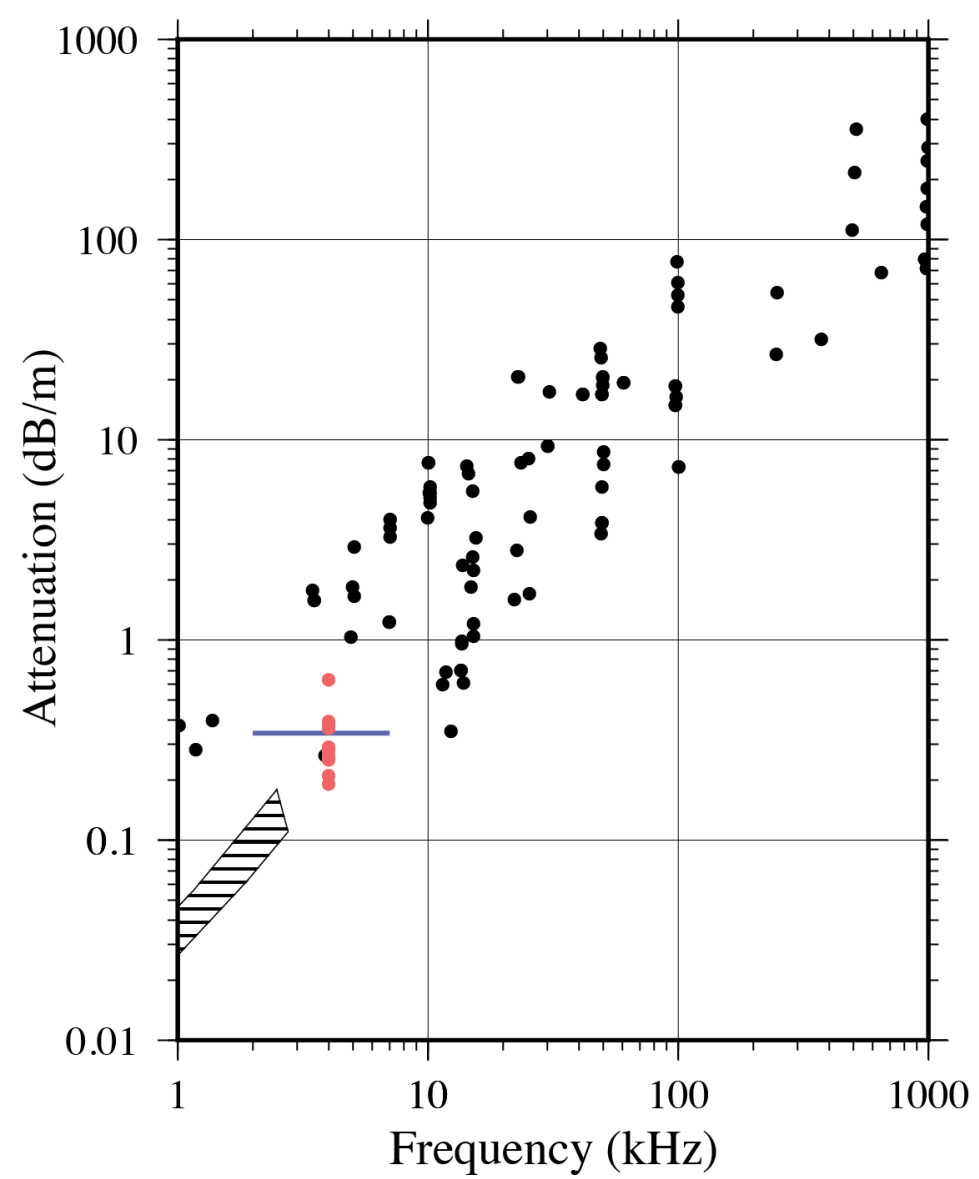

124 Figure 1. Attenuation coefficients of marine sediments from Mitchell (1993), with

125 data originally from Hamilton (1980). Attenuation values for finer grained

126 sediments tend to be smaller and values for sand grade sediment higher at a given

127 frequency. Blue bar represents attenuation coefficient of $0.34 \mathrm{~dB} \mathrm{~m}^{-1}$ over $2-7 \mathrm{kHz}$

128 range for the Chirp data in Figure 2. Red circles represent attenuation measurements

129 made by Tyce (1981) at $4 \mathrm{kHz}$ using data collected with the Scripps Deep Tow over

130 the Southern California Borderland (terrigenous sandy silt to clayey silt) and Rockall

131 Trough (hemipelagic turbidites with silty clay with silt and sand layers). 


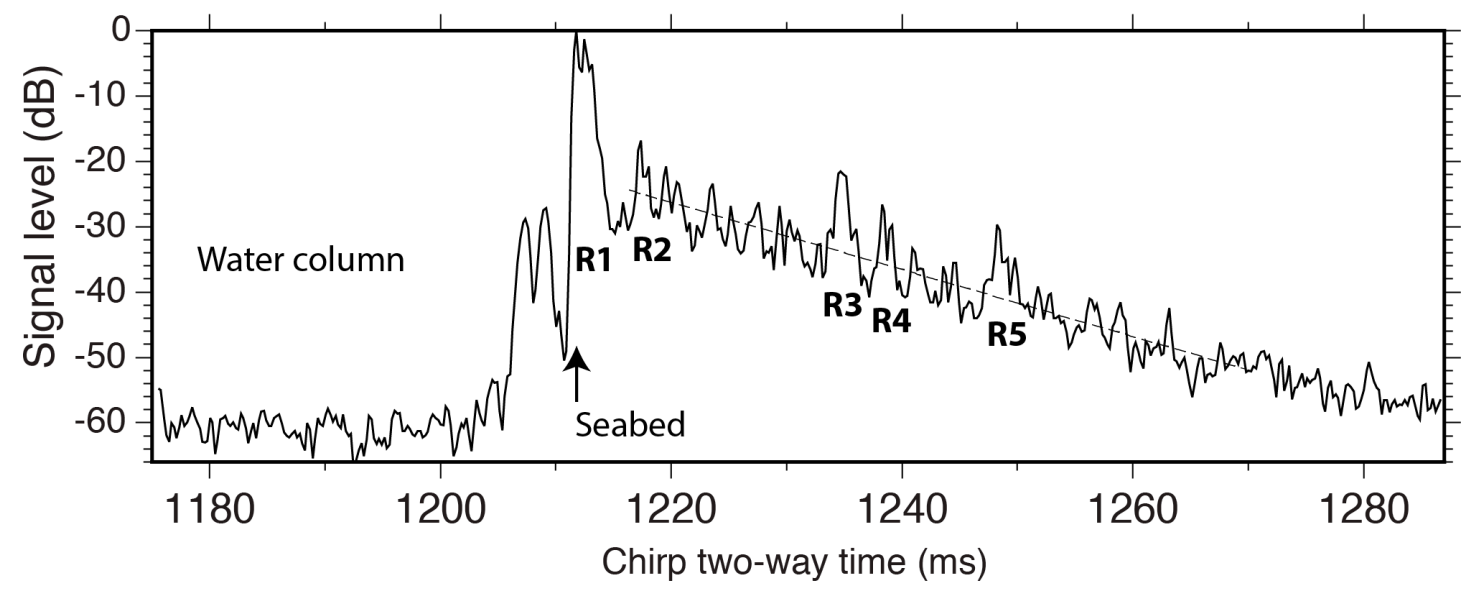

134 Figure 2. Chirp data amplitudes (average of 6 traces) collected in the central Red Sea

135 (data corresponding to Figure 9 of Mitchell et al. (2015)). Amplitudes are plotted in

136 decibels relative to the seabed reflection amplitude (i.e., $20 \log _{10}\left(A / A_{0}\right)$, where $A$ is the

137 data amplitude and $A_{0}$ is the seabed reflection amplitude). Dashed line is simple least

138 squares regression used to quantify the systematic trend in the data over the extent of

139 two-way time covered by the dashed line. R1 to R5 are prominent reflections referred 140 to in the text.

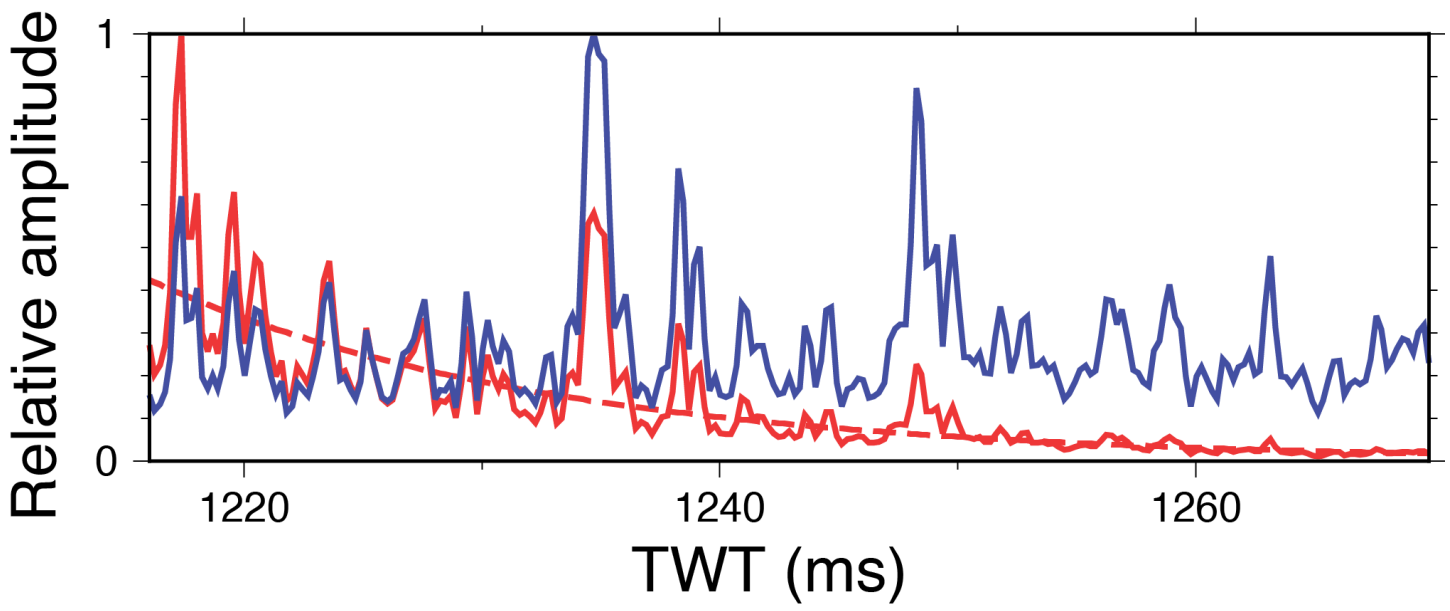

143 Figure 3. The data of Figure 2 plotted as linear amplitudes (red) and the result of de-

144 trending (blue). Dashed red curve shows the regression line of Figure 2. Amplitudes 145 are shown relative to maximum amplitude. 


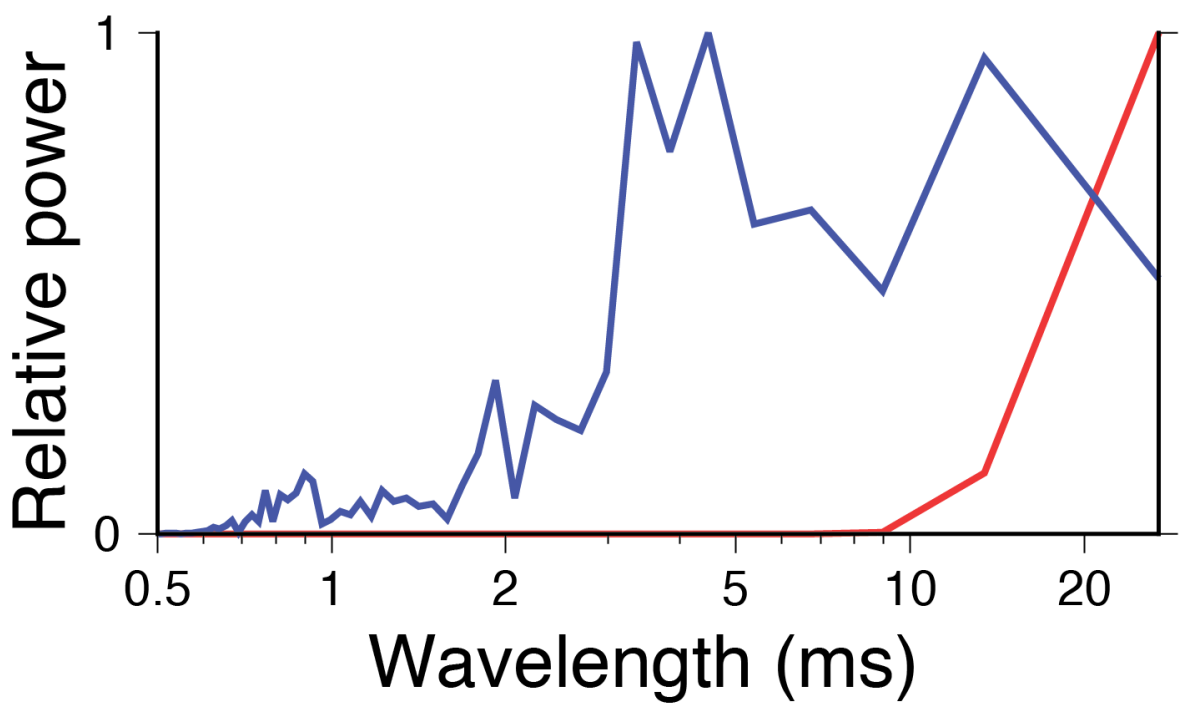

148 Figure 4. Power spectra computed from the data in Figure 3 (line colours correspond 149 with those in Figure 3). 